\title{
Perception of Preparers and Users on Sustainability Reporting in Singapore
}

\author{
${ }^{*}$ Hwang Soo Chiat ${ }^{1}$, Khoo Teng Aun ${ }^{1}$, Wong Dan Chi $^{2}$ \\ ${ }^{1}$ Singapore Management University, Singapore \\ ${ }^{2}$ Paia Consulting Pte Ltd, Singapore \\ *schwang@smu.edu.sg
}

\begin{abstract}
The trend of sustainability reports has increased inexorably as the clamor by various stakeholders including NGOs have been growing louder and louder. In Singapore only a small percentage of listed companies are voluntary providing sustainability reporting but this number is set to increase in line with the world trend. This study attempts to address the perceptions of the importance and usefulness of sustainability reporting, the reporting framework and the training needs of both users and preparers to provide such reports. The results from a survey suggest that the respondents (both undergraduates and managers) perceive sustainability reporting positively and there is a need to provide training especially in the area of integrating financial reporting with sustainability reporting.
\end{abstract}

Keywords: Sustainability reporting, perception, companies

\section{Introduction}

History of sustainability reporting: The sustainability reporting movement began in the 1980s with an initial focus on environmental issues. It quickly gained momentum in Europe in the 1990s, when the European Commission developed a framework for Environmental Management Assessment (EMAS) reporting. By 2000, more than 5,000 firms have produced EMAS reports. Today, sustainability reporting covers environmental, social and economic impacts.Figure1 illustrates how the output by type has evolved from environmental and safety, to include social aspects, to what is termed as sustainability or environment, social and governance (ESG) today. The Global Reporting Initiative (GRI) Guidelines has grown to be the most widely used framework, largely because it was developed through "a consensusseeking, multi- stakeholder process" and has remained freely available.

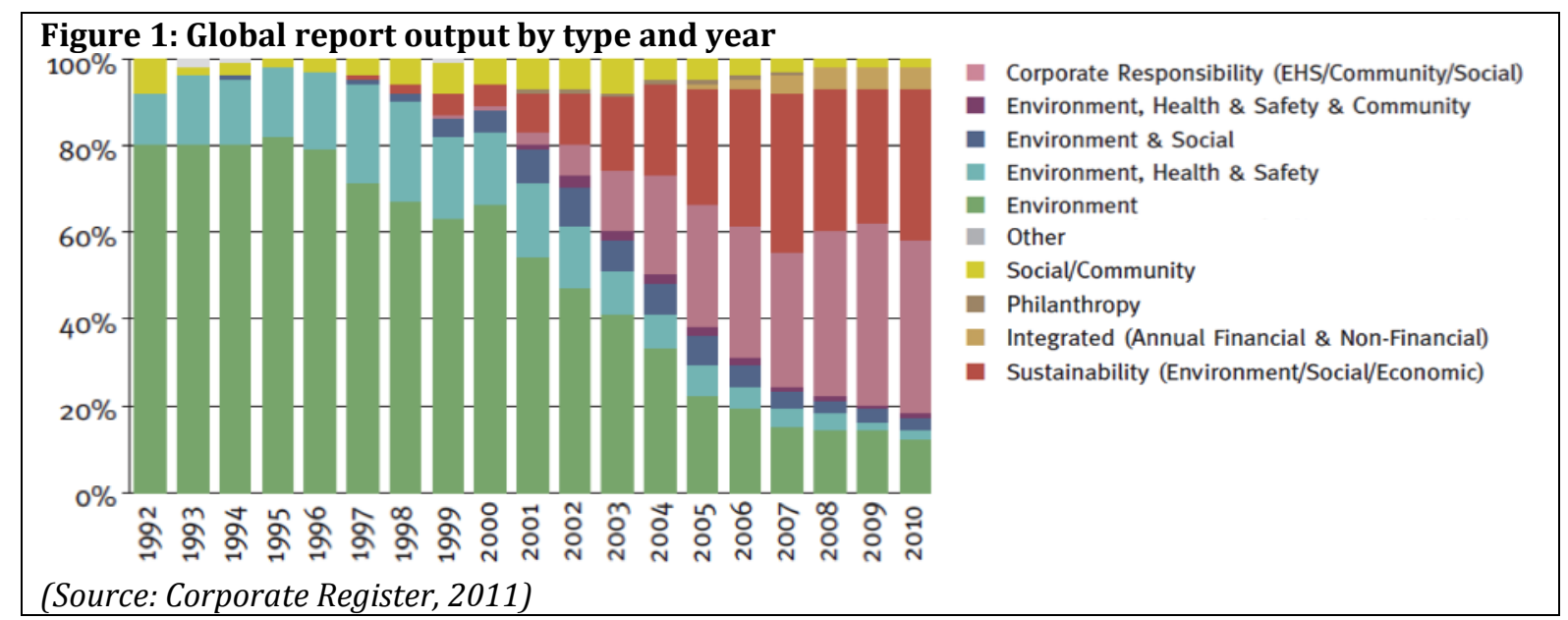

Value of sustainability reporting: Proponents suggest that sustainability reporting builds trust through increased accountability, particularly on issues raise by stakeholders such as non-governmental organizations (e.g. Greenpeace etc). Sustainability reporting is also seen to provide more critical information on companies as valuation of a firm is increasing based on intangible factors - from $17 \%$ in 1975 to 81\% in 2009 (International Integrated Reporting Council, 2011). Meanwhile, there is a growing pool of research suggesting that companies who attend to sustainability issues are better managed and make better investments. In 2010, McKinsey surveyed nearly 2,000 executives and investors. More than $75 \%$ of them said that ESG initiatives create corporate value in the long term (McKinsey Global Survey, 2011). More recently, a study by Harvard Business School showed that sustainability-focused companies outperform their peers as much as $40 \%$ in the long term (Eccles, Ioannoa \& Serofeim, 2012, Harvard 
Business School). These studies were conducted against the backdrop of global financial crisis, which blamed a "short-termism" investment and management approach as well as increased pressure from investors to consider ESG issues as part of the corporate governance process. In New Zealand, pension funds can only invest in firms that produce a sustainability report. Globally, the amount of Responsible Investing and ESG funds are also increasing, further supporting the business case for sustainability reporting. In Europe alone, investment strategies integrating certain ESG criteria totalled €5 trillion at the end of 2009, an 87\% increase from 2007 (Eurosif, 2010).

Mandatory and voluntary regulations: Governments, state-owned companies and stock exchanges have also taken initiatives to encourage sustainability reporting, either mandatory or voluntary. Many countries in Europe have made it a requirement to provide a sustainability report, either as part of the annual report or as a stand-alone report. In South Africa, listed companies are required to produce an integrated report, with both traditional financial and sustainability information. In Asia, countries with mandatory legislations for sustainability reporting include China, India, Japan, Malaysia and Pakistan. Singapore, Hong Kong and Thailand have released voluntary guidelines. In 2011, Hong Kong has also developed the Hang Seng Corporate Sustainability Index Series to promote corporate social responsibility in the marketplace.

\section{Sustainability Reporting in Singapore}

Sustainability reporting in Singapore has increased over the last few years, although more slowly than in other Asian countries like Malaysia and Hong Kong. Singapore, as a major financial hub in Asia is also caught up in the tide, and more and more companies are jumping on the "green wagon" and are providing sustainability reports even though it is not a requirement by the government or by its stock exchange. Based on the findings of Sherman Tan, Principal Consultant \& Director at Innovar Pte Ltd, $14 \%$ of the 562 listed companies in the Singapore Exchange (SGX) were engaged in sustainability reporting in 2010/2011 ("More on Sustainability Reporting", 31 August 2012). SGX itself produced its first GRI report in 2009.0n 27 Jun 2011; Singapore Exchange (SGX) launched Guidelines to Sustainability Reporting, following a public consultation in August 2010 over accountability for conducting businesses in a sustainable manner." On 2 May 2012, the revised Code of Corporate Governance, administered jointly by SGX and Monetary Authority of Singapore (MAS), also reflected a growing importance in sustainability. In particular, Paragraph 1.1(f) of the revised Codestates: "the Board's role is to consider sustainability issues, e.g. environmental and social factors, as part of its strategic formulation".

Purpose of this paper: As sustainability reporting has been growing with increasing importance and usefulness throughout the world, this paper attempts to evaluate the perceptions of sustainability reporting in Singapore and to understand the training needs of potential users and preparers of sustainability report. A questionnaire survey was sent in October/November 2011 to corporate managers as well as undergraduates (UG) in both the Bachelor of Accountancy (BAcc) program and the Bachelor of Business Management (BBM) program in Singapore Management University (SMU). In total, 143questionnaires (see Table 1) were sent to corporate managers in various firms that are both currently engaged in sustainability reporting as well as those who have yet to embark on sustainability reporting, as well as to the undergraduates (consisting of freshmen, sophomore, and senior students).Instruction to the respondents included a short introduction to sustainability reporting (see Appendix 1). The reasons to sending the questionnaires to both UG and managers is to understand the differences between the two groups and to take into account such differences in planning the different needs for Sustainability Reporting courses.

Table 1: Response Rate of Questionnaires issued

\begin{tabular}{lllllllllll}
\hline & \multicolumn{2}{l}{ UG BAcc } & \multicolumn{2}{l}{ UG BBM } & \multicolumn{2}{l}{ Total UG } & \multicolumn{2}{l}{ Managers } & \multicolumn{2}{l}{ Total } \\
\hline & Nos. & $\%$ & Nos. & $\%$ & Nos. & $\%$ & Nos. & $\%$ & Nos. & $\%$ \\
Total issued & 42 & 100 & 65 & 100 & 107 & 100 & 36 & 100 & 143 & 100 \\
Usable responses & 32 & 76 & 35 & 54 & 67 & 63 & 21 & 58 & 88 & 61.5 \\
\hline
\end{tabular}

\section{Results}

Importance, Usefulness\& Costs in Sustainability Reporting 
Table 2: Importance of disclosing non-financial information

\begin{tabular}{lllllllllll}
\hline & \multicolumn{2}{c}{ UG BAcc } & \multicolumn{2}{c}{ UG BBM } & \multicolumn{2}{c}{ Total UG } & \multicolumn{2}{c}{ Managers } & \multicolumn{2}{c}{ Total } \\
& Nos. & $\mathbf{\%}$ & Nos. & \% & Nos. & \% & Nos. & \% & Nos. & \% \\
\hline Very important & 10 & 31.3 & 11 & 31.4 & 21 & 31.3 & 8 & 38.1 & 29 & 33.0 \\
Important & 17 & 53.1 & 17 & 48.6 & 34 & 50.7 & 11 & 52.4 & 45 & 51.1 \\
Sub-total & 27 & 84.4 & 28 & 80.0 & 55 & 82.1 & 19 & 90.5 & 74 & 84.1 \\
Maybe important & 5 & 15.6 & 6 & 17.1 & 11 & 16.4 & 2 & 9.5 & 13 & 14.8 \\
Unimportant & 0 & 0 & 0 & 0 & 0 & 0 & 0 & 0 & 0 & 0.0 \\
Very unimportant & 0 & 0 & 1 & 2.9 & 1 & 1.5 & 0 & 0 & 1 & 1.1 \\
TOTAL & 32 & 100 & 35 & 100 & 67 & 100 & 21 & 100 & 88 & 100 \\
\hline
\end{tabular}

As can be seen from Table 2, respondents when asked if disclosing non-financial information as found in sustainability report was important, at least $80 \%$ of the respondents in each of the three groups deemed it as important or very important. Respondents were then asked if it was useful to disclose non-financial information as found in sustainability report. In line with the responses of the importance of disclosing non-financial information, Table 3 indicates that at least $80 \%$ of the undergraduate groups deemed disclosure of non-financial information to be either very useful or useful.

Table 3: Usefulness of reporting of non-financial information

\begin{tabular}{lllllllllll}
\hline & \multicolumn{2}{c}{ UG BAcc } & \multicolumn{2}{c}{ UG BBM } & \multicolumn{2}{c}{ Total UG } & \multicolumn{2}{c}{ Managers } & \multicolumn{2}{c}{ Total } \\
& Nos. & \% & Nos. & \% & Nos. & \% & Nos. & \% & Nos. & \% \\
\hline Very useful & 5 & 16.1 & 7 & 20.0 & 12 & 17.9 & 6 & 28.6 & 18 & 20.5 \\
Useful & 21 & 64.5 & 21 & 60.0 & 42 & 62.7 & 8 & 38.1 & 50 & 56.8 \\
Subtotal & 26 & 80.6 & 28 & 80.0 & 54 & 80.6 & 14 & 66.7 & 68 & 77.3 \\
Maybe & 6 & 19.4 & 6 & 17.1 & 12 & 17.9 & 7 & 33.3 & 19 & 21.6 \\
Not quite useful & 0 & 0 & 1 & 2.9 & 1 & 1.5 & 0 & 0 & 1 & 1.1 \\
Not useful & 0 & 0 & 0 & 0 & 0 & 0.0 & 0 & 0 & 0 & 0.0 \\
TOTAL & 32 & 100 & 35 & 100 & 67 & 100 & 21 & 100 & 88 & 100 \\
\hline
\end{tabular}

However, only $66.7 \%$ of the managers deemed disclosure of non-financial information to be very useful or useful. This could be perhaps due to the naiveness of the undergraduates or inexperience in the work place. Interestingly, despite the "skepticism" of the managers, none deemed disclosure of non-financial information to be not useful at all.

Table 4: Willingness to disclose non-financial information

\begin{tabular}{lllllllllll}
\hline & \multicolumn{1}{l}{ UG BACC } & \multicolumn{2}{c}{ UG BBM } & \multicolumn{2}{c}{ Total UG } & \multicolumn{2}{c}{ Managers } & \multicolumn{2}{c}{ Total } \\
& Nos. & \% & Nos. & \% & Nos. & \% & Nos. & \% & Nos. & \% \\
\hline Yes & 21 & 65.6 & 27 & 77.1 & 48 & 71.6 & 11 & 52.4 & 59 & 67.0 \\
Maybe & 2 & 6.3 & 1 & 2.9 & 3 & 4.5 & 3 & 14.3 & 6 & 6.8 \\
No & 9 & 28.1 & 7 & 20.0 & 16 & 23.9 & 7 & 33.3 & 23 & 26.2 \\
TOTAL & 32 & 100 & 35 & 100 & 67 & 100 & 21 & 100 & 88 & 100 \\
\hline
\end{tabular}

Despite acknowledging the importance and usefulness of providing non-financial information, when asked whether they would-be willing to issue Sustainability Report/Integrated Report if they were in the position to do so, $28.1 \%$ of the BAcc undergraduates and $33.3 \%$ of the managers indicated their unwillingness to do so (see TABLE 4) citing the costs (actual and hidden) and the unintended (negative) consequences of Sustainability Reporting as the main factors that would prevent them from issuing a sustainability report/integrated report. Other reasons provided includes "not useful for non-listed companies" and "investors only want financial information". These reasons provided may be another possible reason for the lower degree of usefulness assigned by managers in Table 3 .

On the other hand, those who were willing to provide non-financial information gave reasons such as "improved firm's reputation; acknowledged firm's risks; improved firm's performance; showed the level of commitment company had for its stakeholders; and geared company towards long-term holistic planning by making the employees more aware of how even non-financial events and activities can affect the firm's bottom line." 
Table 5: Years needed to reap benefits from reporting of non-financial information

\begin{tabular}{lllllllllll}
\hline & \multicolumn{3}{c}{ UG BAcc } & \multicolumn{2}{c}{ UG BBM } & \multicolumn{2}{c}{ Total UG } & \multicolumn{2}{c}{ Managers } & \multicolumn{2}{c}{ Total } \\
Years & Nos. & \% & Nos. & \% & Nos. & \% & Nos. & \% & Nos. & \% \\
\hline 1 to 3 & 0 & 0 & 6 & 17.1 & 6 & 9.0 & 4 & 19.0 & 10 & 11.4 \\
4 to 5 & 15 & 46.9 & 19 & 54.3 & 34 & 50.7 & 12 & 57.1 & 46 & 52.3 \\
6 to 7 & 12 & 37.5 & 7 & 20.0 & 19 & 28.4 & 3 & 14.3 & 22 & 25.0 \\
8 to 10 & 3 & 39.4 & 2 & 5.7 & 5 & 7.5 & 1 & 4.8 & 6 & 6.8 \\
> 10 & 2 & 6.2 & 1 & 2.9 & 3 & 4.5 & 1 & 4.8 & 4 & 4.5 \\
TOTAL & 32 & 100 & 35 & 10 & 67 & 100 & 21 & 100 & 88 & 100 \\
\hline
\end{tabular}

$52.3 \%$ of all respondents were generally of the view that benefits associated with reporting of nonfinancial information could only be reaped in 4 to 5 years (see Table 5), with only about $11 \%$ of the overall respondents expecting to reap the benefits within three years of reporting non-financial information. It is surprising to see that the BAcc group did not see the possibility of reaping the benefits from 1 to 3 years. A possible explanation for this could be that accounting undergraduates because of the nature of their training tend to be more conservative in their estimation.

Table 6: Possibility of drawing meaningful links between financial and non-financial information

\begin{tabular}{lllllllllll}
\hline & \multicolumn{2}{l}{ UG BAcc } & \multicolumn{2}{c}{ UG BBM } & \multicolumn{2}{c}{ Total UG } & \multicolumn{2}{c}{ Managers } & \multicolumn{2}{c}{ Total } \\
& Nos. & $\mathbf{9}$ & Nos. & $\mathbf{9}$ & Nos. & \% & Nos. & \% & Nos. & \% \\
\hline Possible & 24 & 75 & 23 & 66 & 57 & 85.1 & 16 & 76 & 73 & 83.0 \\
Not possible & 8 & 25 & 11 & 31 & 19 & 28.4 & 5 & 24 & 24 & 27.3 \\
Maybe & 0 & 0 & 1 & 3 & 1 & 1.5 & 0 & 0 & 1 & 1.1 \\
TOTAL & 32 & 100 & 35 & 100 & 67 & 100 & 21 & 100 & 88 & 100 \\
\hline
\end{tabular}

Framework for Reporting

Table 7: Need for an overarching framework for reporting of non-financial information

\begin{tabular}{lllllllllll}
\hline & \multicolumn{3}{l}{ UG BAcc } & \multicolumn{2}{c}{ UG BBM } & \multicolumn{3}{c}{ Total UG } & \multicolumn{3}{c}{ Managers } & Total \\
& Nos. & \% & Nos. & \% & Nos. & \% & Nos. & \% & Nos. & \% \\
\hline Yes & 27 & 84.4 & 22 & 62.9 & 49 & 73.1 & 18 & 85.7 & 67 & 76.1 \\
No & 5 & 15.6 & 13 & 37.1 & 18 & 26.9 & 3 & 14.3 & 21 & 23.9 \\
TOTAL & 32 & 100 & 35 & 100 & 67 & 100 & 21 & 100 & 88 & 100 \\
\hline
\end{tabular}

One key grouse of the respondents appeared to be the compatibility of non-financial information with financial information, which would make comparison of such information within firm and across firms much more difficult. Respondents generally agreed that there was a need to have an overarching framework for reporting both financial and non-financial information as it would make it easier for users and preparers of such statements. An important finding from this survey was that $76.1 \%$ of the total respondents felt that there was a need for an overarching framework to make disclosure of non-financial information useful (Table 7). The respondents suggested that the overarching framework would make it simpler to report non-financial information and enable greater comparability of the reported information.

Table 8A: Awareness of GRI/ IR frameworks/standards in Sustainability Reporting

\begin{tabular}{lllllllllll}
\hline & \multicolumn{2}{l}{ UG BAcc } & \multicolumn{2}{c}{ UG BBM } & \multicolumn{2}{c}{ Total UG } & \multicolumn{2}{c}{ Managers } & \multicolumn{2}{c}{ Total } \\
GRI/IR & Nos. & \% & Nos. & \% & Nos. & \% & Nos. & \% & Nos. & \% \\
\hline Aware & 20 & 62.5 & 18 & 51.4 & 38 & 56.7 & 6 & 28.6 & 44 & 50 \\
Not Aware & 12 & 37.5 & 17 & 48.6 & 29 & 43.3 & 15 & 71.4 & 44 & 50 \\
TOTAL & 32 & 100 & 35 & 100 & 67 & 100 & 21 & 100 & 88 & 100 \\
\hline
\end{tabular}

Table 8B: Awareness of ISO frameworks/standards in Sustainability Reporting

\begin{tabular}{|c|c|c|c|c|c|c|c|c|c|c|}
\hline & \multicolumn{2}{|c|}{ UG BAcc } & \multicolumn{2}{|c|}{ UG BBM } & \multicolumn{2}{|c|}{ Total UG } & \multicolumn{2}{|c|}{ Managers } & \multicolumn{2}{|l|}{ Total } \\
\hline & Nos. & $\%$ & Nos. & $\%$ & Nos. & $\%$ & Nos. & $\%$ & Nos. & $\%$ \\
\hline Aware & 16 & 50 & 12 & 34.3 & 28 & 41.8 & 9 & 42.9 & 37 & 42 \\
\hline Not Aware & 16 & 50 & 23 & 65.7 & 39 & 58.2 & 12 & 57.1 & 51 & 58 \\
\hline TOTAL & 32 & 100 & 35 & 100 & 67 & 100 & 21 & 100 & 88 & 100 \\
\hline
\end{tabular}


An interesting finding from the study is the relatively lower level of awareness by managers of sustainability reporting especially in the form of GRI/Integrated Reporting (IR).However, $50 \%$ of all respondents were aware of GRI/IR compared with the ISO standards(42\%)(TABLES8A \&8B). This study also showed that managers were more familiar with ISO than GRI (which is not necessary/compulsory, and is relatively new to managers) as ISOs are frequently encountered in the commercial/industrial sectors.

Table 9: Necessity of standardization of reporting of non-financial information

\begin{tabular}{llllllllllll}
\hline & \multicolumn{2}{l}{ UG BAcc } & \multicolumn{2}{c}{ UG BBM } & \multicolumn{2}{c}{ Total UG } & \multicolumn{3}{c}{ Managers } & \multicolumn{2}{c}{ Total } \\
& Nos. & $\mathbf{\%}$ & Nos. & $\mathbf{\%}$ & Nos. & \% & Nos. & \% & Nos. & \% & \\
\hline Not necessary & 6 & 18.8 & 8 & 22.9 & 14 & 20.9 & 8 & 38.1 & 22 & 25 & \\
Maybe & 9 & 28.1 & 16 & 45.7 & 25 & 37.3 & 4 & 19 & 29 & 33 & \\
Subtotal & 15 & 46.9 & 24 & 68.6 & 39 & 58.2 & 12 & 57.1 & 51 & 58 & \\
Necessary & 17 & 53.1 & 11 & 31.4 & 28 & 41.8 & 9 & 42.9 & 37 & 42 & \\
TOTAL & 32 & 100 & 35 & 100 & 67 & 100 & 21 & 100 & 88 & 100 \\
\hline
\end{tabular}

Interestingly, 58\% of the respondents were of the view that standardization of reporting for non-financial information was not/maybe necessary (TABLE 9) even though they asked for an overarching framework.

Training

Table 10: Need for inclusion of sustainability reporting in formal education

\begin{tabular}{lllllllllll}
\hline & \multicolumn{3}{l}{ UG BAcc } & \multicolumn{2}{c}{ UG BBM } & \multicolumn{2}{c}{ Total UG } & \multicolumn{2}{c}{ Managers } & \multicolumn{2}{c}{ Total } \\
& Nos. & \% & Nos. & \% & Nos. & \% & Nos. & \% & Nos. & \% \\
\hline Yes & 31 & 96.9 & 25 & 71.4 & 56 & 83.6 & 19 & 90.5 & 75 & 85.2 \\
No & 1 & 3.1 & 10 & 28.6 & 11 & 16.4 & 2 & 9.5 & 13 & 14.8 \\
TOTAL & 32 & 100 & 35 & 100 & 67 & 100 & 21 & 100 & 88 & 100 \\
\hline
\end{tabular}

Table 11: Need for short-term professional courses in sustainability reporting

\begin{tabular}{lllllllllll}
\hline & \multicolumn{2}{l}{ UG BAcc } & \multicolumn{2}{c}{ UG BBM } & \multicolumn{2}{c}{ Total UG } & \multicolumn{2}{c}{ Managers } & Total \\
& Nos. & $\mathbf{\%}$ & Nos. & $\mathbf{\%}$ & Nos. & $\mathbf{\%}$ & Nos. & \% & Nos. & \% \\
\hline Yes & 31 & 96.9 & 33 & 94.3 & 64 & 95.5 & 20 & 95.2 & 84 & 95.5 \\
No & 1 & 3.1 & 2 & 5.7 & 3 & 4.5 & 1 & 4.8 & 4 & 4.5 \\
TOTAL & 32 & 100 & 35 & 100 & 67 & 100 & 21 & 100 & 88 & 100 \\
\hline
\end{tabular}

Table 12: Interest in attending short-term professional courses in sustainability reporting

\begin{tabular}{lllllllllll}
\hline & \multicolumn{3}{l}{ UG BAcc } & \multicolumn{2}{c}{ UG BBM } & \multicolumn{2}{c}{ Total UG } & \multicolumn{2}{c}{ Managers } & \multicolumn{2}{c}{ Total } \\
& Nos. & \% & Nos. & \% & Nos. & \% & Nos. & \% & Nos. & \% \\
\hline Yes & 31 & 96.9 & 19 & 54.3 & 50 & 74.6 & 19 & 90.5 & 83 & 94.3 \\
No & 1 & 3.1 & 16 & 45.7 & 17 & 25.4 & 2 & 9.5 & 5 & 5.7 \\
TOTAL & 32 & 100 & 35 & 100 & 67 & 100 & 21 & 100 & 88 & 100 \\
\hline
\end{tabular}

Table 13: Aspects to be covered in short-term professional courses in sustainability reporting

\begin{tabular}{|c|c|c|c|c|c|c|c|c|c|c|}
\hline \multirow[t]{2}{*}{ Area of coverage } & \multicolumn{2}{|c|}{ UG BAcc } & \multicolumn{2}{|c|}{ UG BBM } & \multicolumn{2}{|c|}{ Total UG } & \multicolumn{2}{|c|}{ Managers } & \multicolumn{2}{|c|}{ Total } \\
\hline & Nos. & $\%$ & Nos. & $\%$ & Nos. & $\%$ & Nos. & $\%$ & Nos. & $\%$ \\
\hline $\begin{array}{l}\text { Regulatory and voluntary } \\
\text { trends in non-financial } \\
\text { reporting }\end{array}$ & 17 & 53.1 & 12 & 34.3 & 29 & 43.3 & 16 & 76.2 & 45 & 51.1 \\
\hline $\begin{array}{l}\text { Introduction } \begin{array}{l}\text { to non- } \\
\text { financial } \\
\text { framework }\end{array} \\
\text { reporting }\end{array}$ & 19 & 59.4 & 14 & 40.0 & 33 & 49.3 & 15 & 71.4 & 48 & 54.5 \\
\hline $\begin{array}{l}\text { Valuation techniques of } \\
\text { non-financial information }\end{array}$ & 25 & 78.1 & 18 & 51.4 & 43 & 64.2 & 17 & 81.0 & 60 & 68.2 \\
\hline $\begin{array}{l}\text { Drawing meaningful } \\
\text { linkages between non- } \\
\text { financial and financial } \\
\text { information }\end{array}$ & 27 & 84.4 & 20 & 57.1 & 47 & 70.1 & 18 & 85.7 & 65 & 73.9 \\
\hline
\end{tabular}


Given that a number of respondents were not familiar with sustainability reporting, it was not surprising that most respondents asked for formal education on non-financial reporting to be provided in universities (Table 10). Practically all respondents asked for some form of short-term professional course be organized for them to pick up skills on sustainability reporting (Table 11) and most respondents reported that they would be interested in attending such courses (Table 12). Respondents also asked that courses should cover aspects such as "Regulatory and Voluntary Trends in Non-Financial Reporting; Introduction to Non-Financial Reporting Frameworks; Valuation Techniques of Non-Financial Information; and Drawing Meaningful Linkages between Non-Financial and Financial Information" (Table 13). Perhaps this is a reflection of the realization of the growing demand for companies to report nonfinancial information and the required skills necessary for meeting this demand that made the respondents interested in acquiring such skills. It is also interesting to note that the BBM undergraduates although recognizing the need for Sustainability Reporting training are less interested $(54.3 \%$ vs the overall average of $94.3 \%$ ) to attend short-term professional courses. This is perhaps due the nature of their course where more emphasis is put into operations (e.g. marketing, logistics, and human resources) rather than the reporting of financial and non-financial information.

\section{Conclusion}

Generally, most respondent indicated that Sustainability Reporting was both important and useful. However taking into account costs factors in Sustainability Reporting would make it less appealing as the benefits may be difficult to quantify. Nevertheless, Sustainability Reporting would continue to grow in importance as sustainability issues would become one of the most pressing needs the world would have to face. The respondents recognized that owing to the compatibility and the voluminous amount of data, a structured framework and standardization would go a long way in Sustainability Reporting, which would incorporate both financial and non-financial information and thus assisting users and preparers of such reports. As the respondents recognized the importance of Sustainability Reporting, they indicated the need in training in Sustainability Reporting in both short-term courses and formal university education. Therefore, most respondents were interested in attending courses related to Sustainability Reporting particularly in the area of linking financial and non-financial information so that it would become more meaningful to read and understand Sustainability Reporting.

\section{References}

More on Sustainability Reporting", 31 August 2012, http://www.innovar.com.sg/more.htm\#Past_Articles Corporate Register, CRRA 2011 Global Winners \& Reporting Trends, March 2011, pp 5.

Eccles, R. G., Ioannou, I. and Serafeim, G. (2012). The Impact of a Corporate Culture of Sustainability on Corporate Behavior and Performance, Harvard Business School Working Paper Series 12-035, 23 November.

Eurosif (2010). European SRI Study 2010, November, pp 7-21.

Integrated Reporting Council (2011). Towards Integrated Reporting - Communicating Value in the 21st Century, 12 September, pp 4.

\section{Appendix 1}

\section{Survey on Sustainability and Integrated Reporting in Asia}

This survey will take about $15 \mathrm{~min}$.

Purpose of study: There has been growing demand for greater transparency not just in financial accounting reporting but also management actions that would have an impact on the sustainability of the companies, with the current trend moving towards Integrated Reporting. This study aims to collect data about sustainability and integrated reporting practices in companies and the impact on accounting curriculum in universities.

\section{Definitions for this study:}

Sustainability reporting is defined as disclosure from an organization that "gives information about economic, environmental, social and governance performance", and hence the sustainability - "capacity to endure, or be maintained" - of the organization (GRI). 
Integrated Reporting combines the most material elements of information currently reported in separate reporting strands (financial, management commentary, governance and remuneration, and sustainability) in a coherent whole, and importantly:

- shows the connectivity between them; and

- Explains how they affect the ability of an organization to create and sustain value in the short, medium and long term. (IIRC)

Your particulars will be kept strictly confidential and be used solely for research purposes.

Name:

\section{Part 1 of 4: Importance and Usefulness of Disclosure}

This section questions if it is important and/or useful for non-financial information, such as social and environmental information to be disclosed.

Q1. Do you think it is important for firms to provide non-financial information, in addition to financial information?

1: Not important at all

2: Not important

3: May be important, maybe not

4: Important

5: Very important

Q1a. Why is it not important? Pick as many as relevant to you.

- Investors ultimately look at financial information

- Non-financial information is primarily used to placate NGOs

- Non-financial information demanded are not relevant to our industry

- Non-financial information is not sophisticated enough for users to know how to interpret it

- Others, please specify:

Q1b. Why is it important? Pick as many as relevant to you.

- Non-financial information are important indicators of operational performance of the firm and/or management

- To distinguish company as a sustainable enterprise

- For comparability with financial information

- For inclusion in ethical funds

- Others, please specify:

Q2. How useful do you think disclosure of non-financial information is?

1: Very useful

2: Useful

3: May be useful, maybe not

4: Not quite useful

5: Not useful at all

Q3a. What do you think are the benefits of sustainability and/or integrated reporting? Pick as many as relevant to you.

- Improved reputation/brand name

- Increased market access

- Improved stakeholders' relationship/enhanced communication with stakeholders

- Reduced or mitigate risks/improved risks management

- Increased long-term shareholders' value

- Improved performance evaluation

- Identify areas for cost savings, reduced wastage

- Improved coordination and communication across firm

- Demonstrate environment responsibility

- Improved financial performance in the long run 
Q3b. What do you think are the costs of sustainability and/or integrated reporting? Pick as many as relevant to you.

- Direct costs needed to gather the required information/difficulty in obtaining information

- Direct costs needed to prepare the reports

- Costs needed to modify the existing accounting (information) system in terms of software and hardware

- Costs of assurance to ensure accuracy and relevancy of the report

- Risk of bad publicity if company is transparent in its reporting

Q4. If you are a decision-maker, will you issue a sustainability and/or integrated report if there are no requirements from professional bodies or legislation?

Yes/No

Why?

A more holistic presentation of my company's overall state of health. Investors are increasingly interested in knowing non-financial information in a fast-changing world where financial information may not always reveal the full picture. Social responsibility is a requirement for firms to operate.

\section{Part 2 of 4: Valuation}

This section questions how non-financial information, such as social and environmental information should be disclosed.

Q5. Given that non-financial information has to be disclosed, how should it be disclosed?

- Quantitatively in financial terms only

- Quantitatively in both financial and non-financial terms (e.g., emissions in tons)

- Qualitatively, and quantitatively in both financial and non-financial terms

Q6. Do you think it is possible to draw meaningful links between non-financial and financial information?

1. Impossible

2. Not likely to be possible

3. May be possible

4. Likely to be possible

5. Definitely

Q7. How long do you think it would take for companies to reap the benefits of reporting such information?

- 1-3 years

- 3-5 years

- 5-7 years

- 7-10 years

- More than 10 years

- Never

Part 3 of 4: Standardization

This section questions if standardization is important and the part it plays in Integrated Reporting.

Q8. Do you think it is necessary to standardize how non-financial information is disclosed?

1: Not necessary at all

2: Not necessary

3: May be necessary, maybe not

4: Necessary

5: Absolutely necessary

Q8a. Why is it not necessary? Pick as many as relevant to you.

- It is more important to begin disclosing, before looking at how to standardize

- Non-financial information is subject to geographical and cultural interpretations 
- Each country or different stock exchanges may have their own legislation requirements

- Standards tend to be biased towards beliefs of certain countries or industries, even with multiple stakeholder engagement approaches

- Standards can be abused as a legitimate trade barrier

- Others, please specify:

Q8b. Why is it necessary? Pick as many as relevant to you.

- Information has to be comparable to be meaningful, hence standardization is necessary

- Standardization is an ongoing process for improvement

- There is overwhelming pressure to disclose non-financial information anyway, and standardizing is a natural next step to disclosing information

- Others, please specify:

Q9a. Which of the following frameworks/standards are you aware of?

- IS014001

- OHSAS 18001

- Global Reporting Initiative (GRI)

- ISO26000

- ISAE 3000

- AA1000 Assurance Standard

- AA1000 Stakeholder Engagement Standard

- Integrated Reporting discussion paper (Only draft framework is available)

Q9b. Which of these following frameworks/standards do you use in your study?

- IS014001

- OHSAS 18001

- Global Reporting Initiative (GRI)

- ISO26000

- ISAE 3000

- AA1000 Assurance Standard

- AA1000 Stakeholder Engagement Standard

- Integrated Reporting (Only draft framework is available)

Q10. Do you think there should one overarching framework for Integrated Reporting? Yes/No

Q10a. If Yes, Why?

- Simpler for reporters and users

- Greater comparability

- Others, please specify:

Q10b. If No, Why?

- Status quo works fine

- Different frameworks cater to different needs

- Monopoly by one single organization may make reporting as a money-making venture

- Others, please specify:

\section{Part 3 of 3: Education}

This section questions if current education/training opportunities are sufficient.

Q11. Do you think there is a need for accountants to receive formal education (from professional bodies such as ACCA, ICPAS and universities) on non-financial reporting?

Yes/No

Q12. Is there a need for accountants to receive short-term professional courses on non-financial reporting? Yes/No 
Q13. Will you be interested in such a course?

Yes/No

Q13a. If Yes, which aspects will you like to see covered?

- Regulatory and voluntary trends in non-financial reporting

- Introduction to non-financial reporting frameworks

- Valuation techniques of non-financial information

- Drawing meaningful linkages between non-financial and financial information

- Others, please specify: 